\title{
Formação profissional esportiva: as escolas de futebol como agente promotor da vida escolar dos alunos
}

\author{
Jardel da Rocha Furtado \\ Instituto Federal do Rio Grande do Sul (IFRS) \\ (jardel_furtado@hotmail.com) \\ Michelle Camara Pizzato \\ Instituto Federal do Rio Grande do Sul (IFRS) - Campus Porto Alegre \\ (michelle.pizzato@poa.ifrs.br)
}

\begin{abstract}
Resumo: O esporte no Brasil se constitui como uma das manifestações mais democráticas na atualidade. O fenômeno esportivo atinge variadas classes sociais, gêneros e etnias, transformando os espaços onde ocorrem essas práticas em locais que podem contribuir de forma significativa para formação integral dos jovens em idade escolar, transformando as escolas esportivas em possíveis espaços de educação não-formal, inclusive para formação de atletas profissionais. Dentro deste contexto, o futebol se apresenta como o esporte mais praticado pelos brasileiros, assumindo uma condição de cultura local do País. Esse trabalho tem como objetivo investigar as escolas de futebol como espaço de promoção à manutenção dos estudos na escola formal através das ações de seus professores. Essa abordagem se justifica pelo grande número de crianças e jovens que procuram esses espaços com objetivo de profissionalização e muitas vezes perdem o interesse ou abandonam a escola de educação básica em função da convicção do sucesso esportivo. A pesquisa apresenta abordagem qualitativa com a realização de quatro entrevistas semiestruturadas com profissionais de educação física que atuam como professores de futebol. Foi possível observar que as escolas de futebol contribuem de forma preventiva para que os alunos prossigam seus estudos concomitantemente aos treinamentos e que essas ações em conjunto com as famílias são fundamentais para que se atinja esse propósito. Verificou-se que as escolas de futebol possuem potencial para contribuir positivamente no processo de formação integral dos alunos, intervindo através do diálogo dos professores com os pais e alunos no sentido de identificar a importância da escolaridade no processo de formação dos alunos.
\end{abstract}

Palavras-chave: Escolas de Futebol; Formação de atletas; Educação não-formal.

\section{Professional sports training: soccer schools as an agent promoting students' school life}

Abstract: Sport in Brazil is one of the most democratic manifestations today. The sports phenomenon affects various social classes, genders and ethnic groups, transforming the spaces where these practices occur in places that can contribute significantly to the integral formation of young people of school age, turning sports schools into possible spaces of non-formal education, including for the training of professional athletes. Whintin this contexto, soccer presents itself as the sport most practiced by Brazilians, assuming a condition of local culture of country. This article aims to investigate soccer schools as a space for promoting the maintenance of formal school studies through the actions of their teachers. This approach is justified by the large number of children and young people who seek these spaces with a view to professionalization and often lose interest or drop out of basic education because of the belief in sports success. The research presents a qualitative approach with four semi-structured interviews with physical education professionals acting as soccer teachers. It was observed that soccer schools preventively contribute to the students to pursue their studies concurrently with training and that these actions together with families are fundamental to achieve this purpose. It was found that football schools have the potential to contribute positively to the process of integral student formation, intervening through the dialogue of teachers with parents and students in order to identify the importance of schooling in the process of student formation.

Keywords: Soccer schools; Training of athletes; Non-formal education. 


\section{INTRODUÇÃO}

O futebol no Brasil não é uma unanimidade, mas é incontestável a paixão e a influência que esse esporte exerce na sociedade, tornando-se um patrimônio cultural. Contudo, com o decorrer do tempo, o futebol foi além de uma paixão, profissionalizou-se, e atualmente constitui-se em um grande negócio.

Como consequência dessa profissionalização, Andrade (2016) cita que o esporte como fonte geradora de riquezas passou a ser alvo de investimentos e desde o momento que a lógica de mercado se fez presente nas organizações esportivas, ocorreu a adoção de elementos típicos do universo empresarial.

Dessa maneira, sejam movidos pela paixão, de puro cunho afetivo, ou com a intenção de ascensão econômica, o desporto atrai muitos jovens para a decisão de investir na carreira profissional de atleta de futebol. Contudo, em algumas oportunidades criam expectativas excessivas, priorizando a prática esportiva em detrimento de outras atividades fundamentais da vida pessoal e profissional.

Os estudos de Marques e Samulsky (2009), sobre atletas na fase de transição do esporte amador para o profissional, apontaram que fatores como a escolaridade, a formação inicial, o suporte familiar e social, e o planejamento da carreira são fundamentais para que o atleta saiba lidar com os possíveis sucessos ou decepções na tentativa de seguir na carreira futebolística.

Os mesmos autores relatam que dos cento e oitenta e seis (186) atletas pesquisados, mais do que a metade (51\%) afirmaram não planejar ter outra profissão, e ainda, o mesmo percentual revelou que interrompeu os estudos em algum momento para jogar. A consequência disso é que um número grande de atletas apresentou defasagem em relação a série correspondente à faixa etária e não tem nenhuma outra perspectiva caso a carreira seja interrompida.

Esses dados são preocupantes, visto que a imprevisibilidade da profissionalização no futebol pode acarretar na necessidade de abandono da prática esportiva, por diversos motivos, como uma lesão ou falta de clube interessado. A falta de escolaridade agrava a situação, tanto em função para recolocação em outra profissão, como para uma visão ampliada de mundo e planejamento de carreira.

Para ser atleta profissional de futebol, não há uma exigência mínima de estudos ou certificação, conforme aponta a Classificação Brasileira de Ocupações, documento do Ministério do Trabalho e Emprego que descreve as características e 
habilitações para as profissões no Brasil, sendo esse um fator que contribui para desmotivação dos aspirantes ao profissionalismo.

Cabe ressaltar que existem mecanismos legais que exigem que os clubes formadores forneçam assistência escolar aos atletas. Entretanto, é necessário que o próprio jovem tenha essa consciência de que estudar é importante, para que essa condição não seja meramente um formalismo.

Para que as crianças e jovens atinjam esse nível de conscientização é necessário que ocorra um trabalho conjunto desde o início da sua prática esportiva, que normalmente ocorre bem cedo, através das escolas de futebol. Surge como necessário o envolvimento de todo grupo de profissionais e comunidade inseridos no âmbito das escolas de futebol para introduzir nas rotinas das aulas os princípios da formação humana integral para os alunos.

Diante do exposto, esse trabalho tem o seguinte problema de pesquisa: quais estratégias os professores de futebol utilizam para que os alunos aspirantes a carreira de futebol sigam com interesse na escola de educação formal? O artigo tem como objetivo discutir como as escolas de futebol podem contribuir para que os alunos prossigam os estudos junto as escolas formais mesmo com a prática do treinamento em futebol. Cabe apontar que esse trabalho faz parte do projeto de pesquisa vinculado ao Mestrado Profissional em Educação Profissional (PROFEPT) do Instituto Federal do Rio Grande do Sul intitulado como "Formação de atletas: as escolas de futebol como espaços de educação não-formal em busca da formação integral”

O artigo apresenta uma breve descrição sobre a formação profissional no Brasil, explicitando os principais desdobramentos políticos e culturais que culminaram na concepção da forma de trabalho que conhecemos atualmente. Em um segundo momento serão apresentados os locais e contextos onde ocorrem os processos de formação de profissionais e por fim será enfatizada a proposta de formação para atletas nas escolas de futebol a partir da perspectiva de valorização da escola formal.

\section{A formação profissional no Brasil: uma breve contextualização}

A formação profissional no âmbito da educação brasileira está prevista no artigo 39 da LDB como aquela que abrange os cursos de formação inicial e 
continuada ou qualificação profissional, educação profissional técnica de nível médio e educação tecnológica de graduação e pós-graduação (BRASIL,1996).

De acordo com Moura (2007), a educação profissional surge no Brasil com lógica assistencialista fruto de uma sociedade escravocrata, e foi ao longo do tempo fortemente marcada por uma dualidade de educação, onde a educação básica de caráter propedêutico é dirigida a formação de elites e a educação de caráter instrumental é destinada as classes populares.

Concebida a partir dessa dualidade histórica entre formação geral e formação específica, a educação profissional tornou-se um cenário de discussões entre os que desejavam manter o sistema dual hegemônico e aqueles que visavam a redução dessa dualidade por intermédio de um sistema de ensino que proporcionasse ao aluno uma formação integral.

\section{Os avanços e retrocessos no processo de formação do trabalhador}

Conforme citado anteriormente, a dualidade estabelecida no âmbito educacional teve como objetivo diferenciar a educação oferecida para os que gerenciam ou são proprietários dos bens de serviço, daqueles que são empregados e vendem sua força de trabalho. A manutenção dessa hegemonia e o ambiente educacional como campo de disputa se dá principalmente através dos sistemas de ensino, onde a educação propedêutica fornece uma cultura geral, servindo como via de acesso ao ensino superior, enquanto o ensino profissional serve para futuros subordinados, sendo ofertado aos alunos aulas baseadas em conteúdos instrumentais.

Essa relação dual constitui-se como um fato histórico, com diferentes desdobramentos ao longo do tempo. Manfredi (2002) considera que a relação educação e trabalho já era desempenhada no Brasil com os povos nativos, afirmando que a aprendizagem no interior das tribos ocorria na caça, pesca, plantio e colheita, onde os mais velhos faziam e ensinavam os mais novos. A autora destaca também que muitos foram os desdobramentos e espaços de disputa no campo educacional desde o Período do Brasil Colônia até a criação da Constituição Federal de 1988, sendo esse documento considerado um marco para tentativa de avanço da educação voltada para formação de trabalhadores. 
A Constituição Federal de 1988 permitiu um processo de redemocratização no Brasil e as discussões sobre os rumos da educação foram restabelecidas, culminando em avanços que permitiram a promulgação da nova LDB, documento que normatiza e orienta a educação nacional. Pode-se considerar também como uma evolução para redução da citada dualidade, a criação do Decreto 5.154/04: nesse documento é prevista a possibilidade de integrar o ensino médio a educação profissional, vista como benéfica pelos que defendem o fim do modo dual.

A retomada nas discussões também viabilizou a expansão da Rede Federal de Educação Profissional, através da Lei n¹1.892/2008, permitindo dessa maneira uma significativa colaboração na formação profissional do País, principalmente no que consiste a proposta de ensino médio integrado a educação profissional.

\section{O trabalho como princípio educativo: um objetivo a ser alcançado}

Esse novo cenário de formação profissional trouxe consigo muitas perspectivas e metas a serem alcançadas. A possibilidade prevista de integrar 0 Ensino Médio ao Ensino Profissional surge como uma possibilidade de redução da dualidade histórica estabelecida; contudo, necessitava de um projeto diferenciado daquele tradicional como ideia de educação escolar.

Saviani (2007), inspirado nas reflexões sobre trabalho como princípio educativo da escola unitária de Gramsci, analisa que o sistema educacional mesmo quando não faz referência direta ao processo de trabalho, apresenta implicitamente essa característica. Destaca-se o seguinte trecho da obra do autor:

\footnotetext{
Aprender a ler, escrever e contar, dominar os rudimentos das ciências naturais e das ciências sociais constituem pré-requisitos para compreender o mundo em que se vive, inclusive para entender a própria incorporação pelo trabalho dos conhecimentos científicos no âmbito da vida e da sociedade. (SAVIANI, 2007, p. 160).
}

A escola unitária, citada anteriormente, constitui-se em um modelo proposto por Antonio Gramsci na Itália em 1920, em oposição ao regime educacional implementado pelo regime fascista, no qual "a escola foi posta a serviço da formação da nova mão de obra necessária a atender à organização do capitalismo em ascensão na Itália, típica da nova indústria" (SOBRAL et al.,2016). A oposição não estava relacionada a formação para atividade profissional - Gramsci era contrário à 
forma meramente instrumental de ensino oferecido nas escolas, pois defendia como Escola Unitária aquela que desenvolvesse as capacidades técnicas e intelectuais:

\begin{abstract}
A análise gramsciana admite a necessidade de se reformar o sistema educacional para formar os profissionais da indústria, por enxergar que o problema não se concentra na industrialização e sim na maneira adotada pelo governo para resolver essa problemática, bem como na vinculação ao objetivo de perpetuar a forma de sociabilidade dividida em classes antagônicas, cindada em trabalho manual e intelectual, o que se desdobra na escola através da divisão entre o ensino profissional-manual e o ensino intelectual. (SOBRAL et al. 2016, p. 183).
\end{abstract}

O perfil do aluno egresso da educação unitária sugerido por Gramsci se enquadra nessa nova proposta brasileira. A educação profissional não pode ter como objetivo a formação simplesmente para o trabalho como uma possibilidade de subsistência e com habilidades meramente instrumentais.

Para Frigotto (2009), o trabalho como princípio educativo deve se estabelecer numa perspectiva antagônica às relações sociais capitalistas, onde possa se desenvolver as bases sociais, culturais e científicas das múltiplas dimensões do ser humano, para transição de um novo modo de produção e organização da vida social.

É importante destacar que esse processo de aliar trabalho e educação seria na verdade uma retomada do sentido do trabalho em seus primórdios da civilização. Saviani (1994) aponta que inicialmente a educação coincidia no próprio processo de trabalho, pois enquanto o homem produzia de forma comunitária para sua existência, era educado através desse processo.

Nesse contexto, não havia separação por classes, ou seja, todos trabalhavam e eram educados de forma concomitante. Trabalhando na terra, lidando na natureza e se relacionando entre si, se educavam e educavam as demais gerações.

De acordo com Ramos (2010), a luta histórica e o conceito de integração da educação profissional vão ao encontro da ideia do trabalho como princípio educativo, pois vai além da preocupação com carga horária e currículo, trata-se de uma formação comprometida com o processo de ensino-aprendizagem, conhecimentos gerais e específicos, cultura e trabalho, e humanismo e tecnologia. 


\section{O processo de profissionalização de atletas de futebol}

O sistema hegemônico de separação por classes não atingia somente o sistema educacional, impactava a sociedade como um todo, inclusive alcançava a área esportiva. Retomando a história do nosso esporte mais popular, verificamos que o futebol surgiu no Brasil de maneira amadora e apresenta diferentes versões referente a sua chegada no País. Contudo, a teoria que consta na maioria dos estudos é que foi introduzido por Charles Muller no ano de 1894, que trouxe consigo um livro de regras e bolas, após uma temporada de estudos na Inglaterra.

A introdução do futebol na cultura brasileira, a partir de 1894, passou por diversos períodos até o profissionalismo, que foi oficializado em meados de 1930 . De acordo com Riviti (2016), os primeiros clubes de futebol foram criados com intuito de assegurar aos seus sócios atividades esportivas e recreativas.

Caldas (1990) relata que boa parte da trajetória inicial do Brasil no futebol possui caráter elitista: os precursores do esporte no País foram os ingleses que faziam parte da elite da sociedade paulista e carioca; além deles, somente brasileiros ricos podiam jogar, em função de todo material para prática do jogo ser importado e caro. Rivitti (2016) aponta que entender quem foram os primeiros praticantes e como se estabeleceram como futebolistas nos idos de 1900 é questão central para compreendermos o processo de profissionalização. O autor destaca ainda que a popularização do esporte, gerando aumento de público para assistir aos jogos, contribuiu de forma significativa para o fim da era amadora.

Atualmente são comuns os casos de dirigentes que demitem treinadores ou dispensam jogadores por pressão dos torcedores da equipe. Como podemos analisar, essa intervenção externa no âmbito esportivo não se revela uma novidade. Referente a essas intervenções, destaca:

[...] a pressão por vitórias levou os clubes a buscarem jogadores fora de seus quadros associativos, visando melhorar tecnicamente seu elenco. Estas transações foram 0 ponto de partida para profissionalização do futebol brasileiro. Com a demanda de clubes por melhores jogadores, eles podiam então negociar sua participação, determinando valores por seus préstimos. Como ainda se tratava da era amadora, proibia-se o pagamento de salário por parte das associações esportivas, o que obrigou os clubes a mascararem os pagamentos. (RIVITTI, 2016, p. 25). 
Iniciativas de premiar jogadores por vitórias eram veemente reprimidas em meados de 1920; no entanto, ressaltar, conforme aponta Rivitti (2016), que havia remuneração de forma disfarçada por parte dos clubes aos futebolistas com talento, mesmo se não fossem oriundos de famílias aristocráticas. De acordo com o mesmo autor, o profissionalismo somente seria de fato inaugurado durante o regime do presidente Getúlio Vargas, como parte de um conjunto de medidas do seu governo.

Caldas (1990) aponta que o futebol não estava incluso nessas mudanças, porém, o Programa da Reconstrução Nacional do presidente Vargas permitiu que a profissionalização fosse vislumbrada. A profissionalização foi de fato oficializada em 1933. “A CLT, sancionada em 1943, estabelece direitos ao esportista. Ainda que o futebol não fosse o principal alvo das reformas, acabou por se beneficiar dos planos para regulamentação do futebolista como profissional no País" (RIVITTI, 2016, p. 30).

Atualmente, a condição de atleta profissional é regulamentada pela Lei 9.615 de 24 de março de 1998 - a mesma define a prática desportiva como não-formal e formal, sendo a primeira caracterizada pela liberdade lúdica dos praticantes e a segunda como aquela regulamentada por regras nacionais e internacionais, assim como entidades de administração do desporto.

No âmbito do futebol brasileiro, o órgão responsável pelo registro de atletas profissionais é a Confederação Brasileira de Futebol:

A Confederação Brasileira de Futebol (CBF) tem como principal
objetivo liderar e promover a prática esportiva do futebol no Brasil.
Iniciou suas atividades em 20 de agosto de 1916, como parte
integrante da Confederação Brasileira de Desportos (CBD), uma
entidade compromissada com o desenvolvimento desportivo do
Brasil. Em 1923, a CBD foi admitida ao quadro de confederações
filiadas à Fédération Internationale de Football Association, a FIFA,
órgão máximo e de expressão mundial na gestão do futebol. (CBF,
2017)

Conforme demonstrado, o atleta de futebol profissional deve ter seu registro efetuado junto a CBF para que esteja devidamente regularizado para atuar profissionalmente. Cabe ainda ressaltar que a FIFA é órgão máximo no mundo dentro da hierarquia do futebol.

De acordo com o Regulamento Nacional de Registro e Transferência de Atletas de Futebol da CBF, são considerados atletas profissionais de futebol no 
Brasil aqueles que exercem a sua atividade desportiva em cumprimento a um contrato formal de trabalho desportivo, firmado e registrado na CBF vinculado a uma entidade esportiva, os chamados clubes de futebol.

Angelo (2014) pondera que na possibilidade de verificar o sentido do trabalho no segmento do futebol profissional brasileiro e seu papel na sociedade atual, é importante lembrar que o trabalho como atleta de futebol é apenas mais um dentre tantos outros, onde o trabalhador vende sua força de trabalho com o valor de troca regulado pelas leis da oferta e procura do mercado. Diante do exposto, fica evidente que a função de atleta de futebol está consolidada no cenário brasileiro como uma prática profissional, pois apresenta regulamentação e todos os demais componentes da lógica de mercado.

\section{Da marginalização ao sonho de criança: um panorama sobre a evolução na percepção sobre a carreira do atleta de futebol}

A classe elitista temia a democratização no esporte em sua época amadora, pois havia o receio de que atraísse praticantes que não fossem da elite. Esse temor acabou se concretizando quando em 1923 o Clube de Regatas Vasco da Gama decidiu colocar em sua equipe negros e mulatos de classe operária e brancos analfabetos, e por ironia, tornou-se campeão carioca enfrentando equipes que lutavam pelo elitismo no futebol (CALDAS,1990).

Nesse tempo, conforme afirma Carravetta (2006), o futebol representava uma distinção da elite brasileira na qual, nas tribunas dos campos esportivos, predominavam pessoas de bom nível econômico e cultural com roupas elegantes para torcer para seus filhos ou familiares. Pobres, negros e mulatos eram excluídos do esporte e praticamente não frequentavam os campos.

Diante desse novo panorama criado pelo Clube de Regatas Vasco da Gama, Caldas (1990) nos revela que imediatamente cria-se um preconceito com o jogador de futebol, que nasce justamente do desejo das elites em não ter qualquer identidade com outros segmentos da sociedade. Esse fenômeno não é considerado pelo autor como um fato sociológico e sim histórico, visto que, em nenhum momento a classe dominante desejou identidade com as demais classes sociais.

A inclusão de um número expressivo de jogadores de origem popular na equipe vascaína e a conquista do Campeonato Carioca foi o marco do rompimento 
da discriminação, que contribuiu decisivamente para a popularização e massificação do futebol (CARRAVETTA, 2006).

Para a elite, a partir desse momento, jogar futebol deixa de ser uma atividade nobre para ser um esporte grosseiro, da qual ela se afasta, mudando dessa forma a imagem de jogador, fazendo com que o prestígio da atividade suma, tornando-se um esporte de "gentinha" (CALDAS, 1990).

Contudo, a mudança radical ocorreu de fato a partir da profissionalização de 1933 - a partir daí sucedeu-se um período de muitas discussões e planejamento do futebol brasileiro até chegarmos na estrutura atual. Hoje o futebol ocupa um espaço privilegiado no mundo global dos negócios e na indústria do entretenimento, e os clubes necessitam implementar a profissionalização em suas estruturas técnicas e administrativas para lidar com as receitas das instituições (CARRAVETTA, 2006).

A consequência desse novo conceito e organização dos clubes mudou novamente a característica do futebol. O desporto que teve origem burguesa e perdeu seu prestígio posteriormente, sendo inclusive marginalizado, agora atrai grandes investimentos, alterando novamente o perfil de parte dos atletas de futebol. Carravetta (2006) destaca que o futebol como espetáculo, produto da indústria cultural, configura-se um dos ramos mais lucrativos da economia e serviços de entretenimento, tornando-se um negócio milionário.

Esse contexto atual do futebol é amplamente apresentado nos meios de comunicação, evidenciando a figura do atleta com boa remuneração, que possui bens materiais e vida bem-sucedida. Apesar de ser uma realidade o pagamento de altos salários para alguns atletas de futebol, deve se deixar claro que isso ocorre em clubes bem estruturados e para um número reduzido de atletas, considerados de excelência.

Correia (2018) aponta que dados da CBF revelam que dos 28.203 atletas registrados em 2015, exatos 23.238 ganhavam até mil reais, pouco mais do que um salário mínimo na época, e somente 765 atletas ganhavam acima de dez mil reais. Esses indicadores demonstram que o mercado profissional de jogadores de futebol, além de não empregar muitas pessoas, paga valores relativamente baixos para grande maioria dos profissionais, se comparada à média salarial brasileira em 2016 que era de dois mil e duzentos e vinte sete reais.

A impressão de que a profissão de jogador de futebol é garantia certa de sucesso e boa remuneração se deve principalmente ao fato de que os principais 
clubes ocupam os noticiários de jornais, espaços publicitários e aparecem em horário nobre na televisão. A esperança de grandes cifras, possibilidade de exposição, receber patrocínios e a crença difundida na mídia sobre profissional bem pago, criam na cabeça dos aspirantes que basta ter habilidade e mérito pessoal para atingir o sucesso (CORREIA, 2018).

Todo esse cenário contribui para que crianças e jovens sonhem estar no lugar dos seus ídolos e constrói no imaginário do público que o estilo de vida apresentado é o padrão para profissão. A possibilidade de ascensão através do esporte atrai principalmente crianças e jovens de camadas populares, muitas vezes incentivados pelos pais, que veem no desporto uma oportunidade de mudar de vida.

\section{Contribuições das escolas de futebol no processo de formação dos atletas}

As escolas de futebol, popularmente chamadas de "escolinhas", são os espaços onde são oferecidas aulas do esporte e podem apresentar caráter distintos, dependendo do ambiente onde são desenvolvidas. Existem as escolas dos clubes profissionais de futebol, clubes sociais, contraturno escolar em escolas formais de tempo integral, comunitárias, em condomínios privados, entre outras. Do estudo de Rocha (2017, p. 150), que analisou por meio de entrevistas, como os jovens observam as oportunidades de profissionalização no futebol, extraímos a seguinte constatação:

Percebam que a apresentação dos jovens atletas entrevistados encontrou um certo padrão para o ingresso deles nas rotinas de treinamento. Vimos que há uma variação entre a origem desses meninos: três jovens são do Rio de Janeiro, três, de São Paulo, dois de Londrina, estado do Paraná, um, de Brasília e um do Ceará. Apesar da variação dos estados de origem, todos tiveram seu primeiro contato com o futebol muito cedo, antes mesmo dos dez anos de idade. Além disso, todos tiveram alguma participação em escolinhas de futebol, sejam elas privadas, vinculadas a clubes de futebol ou não, ou fruto da organização de um projeto social.

Os clubes de futebol possuem, além das escolinhas, outra divisão, que são as escolas específicas de formação; contudo, para ingresso direto nessas escolas é necessário passar por testes, popularmente chamados de "peneiras". Essas avaliações são muito concorridas; dessa forma, um número expressivo de aspirantes 
a jogador opta por iniciar nas escolinhas, por não haver restrições para o acesso e apresentarem uma possibilidade de promoção às escolas de formação dos clubes.

Essa iniciação nas escolinhas é mais comum do que se imagina e consiste em uma tendência atual: antes de iniciar nas escolas de formação do clube, conhecidas também como categorias de base, as escolinhas iniciam o processo de treinamento e disciplinamento dos jovens para que um dia vislumbrem a carreira no futebol como uma oportunidade de sucesso (ROCHA, 2017).

$\mathrm{Na}$ pesquisa de Marques e Samulsky (2009), que entrevistaram cento e oitenta e seis atletas que disputam a divisão principal do Campeonato Brasileiro de Futebol, foi constatado que a rua foi o cenário principal de formação de jovens jogadores de futebol (54,8\%). No entanto, a escolinha, uma instituição esportiva relativamente recente no futebol brasileiro, surge com um percentual relevante $(33,9 \%)$, apontada pelos atletas como o local de aprendizagem inicial do futebol.

Para Couto (2012), as escolinhas de futebol têm suas finalidades relacionadas ao lazer e a saúde; porém, acenam-se como um possível caminho de acesso a grandes clubes e dessa forma cresce a expectativa dos jovens matriculados nessas instituições e de suas respectivas famílias diante da possibilidade de terem a chance de, algum dia, tornarem-se profissionais e brilharem pelo mundo defendendo a camisa de um grande clube. Ou seja, as escolas de futebol, mesmo que não tenham como finalidade a formação de atletas, acabam ocupando esse papel de iniciação precoce a profissão de jogador de futebol. Até mesmo as escolinhas que possuem caráter lúdico acabam acolhendo os aspirantes a profissão, pois não podem restringir o ingresso de novos alunos como ocorre nos processos de seleção.

Dessa maneira, mesmo quando possuem suas intenções bem definidas a respeito do método de trabalho e não tem como objetivo o trabalho visando a profissionalização de atletas, a escolinha de futebol deve estar preparada para receber esse público.

\section{A expansão das escolas de futebol}

De acordo com Freire (2006), o processo de construção do futebol brasileiro se constituiu basicamente no Futebol de Rua: as crianças jogavam nos espaços abertos, como ruas, alamedas ou campos de várzea e desses locais saíram grandes 
jogadores profissionais. Vimos anteriormente que desde a fase de transição do esporte de amador para o profissionalismo, atletas talentosos eram procurados nos subúrbios, onde jogavam em espaços alternativos de prática desportiva, indo ao encontro do que aponta o autor.

O desenvolvimento urbano e o crescimento das grandes metrópoles causaram alterações significativas nessa realidade. Com o aumento do número de construções, muitos locais onde eram campos de várzea, hoje existem residências ou prédios comerciais, reduzindo significativamente o número de espaços livres para prática do futebol de rua ${ }^{1}$. O cenário apresentado proporcionou uma oportunidade para o crescimento das escolas de futebol, visto que as crianças mantinham o desejo de praticar o esporte, mas os locais em espaços abertos sofreram restrições e foram cada vez ficando mais escassos.

Freire (2006) destaca que no tempo em que havia fartura de espaço e de brincadeira, não fazia sentido em falar de escolinha de futebol, pois dos espaços abertos saiam "Didis", "Garrinchas", "Gersons" e "Romários", fazendo referência a jogadores que marcaram época e deram grande contribuição ao futebol brasileiro. Dessa maneira, hoje temos uma vasta oferta de escolas de futebol, de diferentes perfis, podendo ser vinculadas a clubes profissionais ou não e nos mais diferentes espaços, como ginásios, campos de grama artificial, natural ou alguns campos de várzea que ainda restam em determinadas localidades.

\section{A metodologia de ensino das escolas de futebol}

A escola convencional, de ensino formal, é regida por lei e segue diretrizes nacionais que possuem como objetivo oferecer educação similar e de qualidade para todos no Estado brasileiro. Mesmo que isso não ocorra a contento, conforme explicitado nos capítulos iniciais, esse fato deveria ser o comum.

A metodologia das escolas de futebol, apesar de não ser um espaço formal de ensino, também deve possuir planejamento para formação do aluno. Devem ser aprendidos aspectos técnicos do desporto, como os fundamentos e as regras, mas não podem ser desconsiderados as questões culturais que envolvem a prática desportiva, conforme aponta Carravetta (2006, p. 103):

\footnotetext{
${ }^{1}$ Ibid., p. 2
} 
No futebol o desempenho técnico de um jogador é resultado de seu potencial genético, somados aos procedimentos contínuos de ensino-aprendizagem-treinamento, no entanto, a aprendizagem cultural está presente em todos os lugares, em todos espaços, tanto que os estímulos culturais que o envolvem exercem significativa influência na trajetória do seu desenvolvimento técnico.

Freire (2006) defende que para atender os princípios de aprendizagem do futebol tecnicamente bem jogado e, além disso, aprender mais que futebol, é necessário assumir procedimentos que levem o aluno a compreender as próprias ações. São necessárias técnicas pedagógicas para produzir compreensão sobre as ações práticas - com essa conduta, os alunos aprendem a refletir sobre o que é ensinado, dando sentido a esse aprendizado.

$O$ ensino de qualquer prática esportiva deve ser contextualizado com a realidade da sociedade, a metodologia deve prever abordagens sobre o cotidiano da vida do aluno. O futebol ocupa um espaço especial no Brasil, e representa mais que um esporte na cultura do País. As escolas de futebol devem saber explorar essa reconhecida função social para proporcionar uma aprendizagem significativa para vida dos seus alunos.

\section{MATERIAIS E MÉTODOS}

A pesquisa pode ser classificada como exploratória de caráter qualitativo. Para análise da questão levantada na pesquisa, foram realizadas 4 entrevistas semiestruturadas com profissionais de educação física que atuam como professores em escolas de futebol no município de Porto Alegre. Os entrevistados se encontram na faixa etária entre 28 e 34 anos e possuem entre 5 e 13 anos de carreira, sendo que 3 possuem curso de especialização na área de educação física e atendem alunos entre os 9 e 20 anos de idade. As entrevistas foram gravadas, transcritas e categorizadas através de análise de conteúdo. De acordo com Moraes (1999), a utilização dessa técnica de análise conduz a descrições sistemáticas que ajudam a reinterpretar mensagens e atingir uma compreensão de seus significados num nível que vai além da leitura comum. As categorias de análise foram as seguintes: metodologia de ensino no esporte, itinerário formativo no futebol e escolarização. 


\section{RESULTADOS}

A seguir, vamos descrever, a partir da fala dos professores, quais dificuldades, estratégias e potencialidades esses profissionais encontram em seus ambientes de trabalho para demonstrar aos alunos de forma efetiva qual a importância da escolarização.

Metodologia de ensino:

Elaborar um plano de aula é fundamental para organização do professor, pois possibilita a abordagem de temas transdisciplinares, além do conteúdo a ser desenvolvido. Os planos de aula são importantes, independente do espaço em que ocorre o processo de ensino aprendizagem. A partir desse contexto, os professores explicam a respeito de como funciona o método de ensino nas escolas esportivas de futebol:

Professor 1: A gente utiliza a metodologia sistêmica. Bastante treinamento com jogos reduzidos e treinamentos físicos incluindo a bola, dentro de minijogos. Geralmente tem a conversa inicial, um aquecimento, com um alongamento; depois a parte principal, depois uma volta a calma, junto com uma conversa dando um feedback sobre o treinamento.

Professor 2: [...] sempre a gente trabalha com uma conversa inicial com as crianças, um alongamento, explicando porque é importante um alongamento, um aquecimento, que é importante para elas saberem se situarem [...] a parte principal a gente trabalha com um fundamento em si, depois a gente trabalha o fundamento com a questão da conclusão a gol [...] na parte final a gente dá um feedback, como foi a aula, como eles foram, uma conversa, porque fica assim melhor dividida a aula. Parte inicial, parte principal e parte final.

Professor 3: O treino se divide geralmente em um primeiro momento com aspectos iniciais coordenativos ou técnicos, um segundo momento com trabalho situacional e concluindo o jogo, com formato de jogo mesmo, jogo reduzido ou alguma adaptação. 
Professor 4: As partes das aulas têm parte inicial de alongamento, aquecimento, com brincadeiras, trabalhando com futebol moderno, que cada vez a gente trabalha muito mais com a bola, então tanto em treinos físicos ou aquecimento procurar usar bastante a bola, mas com parte inicial, desenvolvimento e parte final, sempre com o jogo.

Itinerário formativo:

Considera-se como itinerário formativo nesse artigo, a trajetória que o aluno que deseja ser profissional no futebol precisa construir e as áreas que devem ser desenvolvidas para atingir o profissionalismo. Nesse sentido, os professores relataram que as escolas podem contribuir da seguinte maneira:

Professor 1: A gente vai conversando aos poucos né, explicando a questão de que todo mundo tem o sonho de ser jogador, da realidade que é bem complicada, bem difícil. Para os mais jovens a gente vai com um pouquinho mais de calma né, para também não frustrar tanto. Com os mais velhos das idades finais ali 16, 17, a gente já vai já comentando sobre o que tá pensando, se já quer estudar, ir para uma faculdade, essas coisas. A gente vai dando uns conselhos assim, também já pra ir mostrando que daqui a pouquinho não vai dar, mas tem uma saída.

Professor 2: A gente sempre procura passar para eles que o futebol é importante, o esporte é importante, e a gente tenta sempre trabalhar a motivação dos alunos dentro da aula né, para que eles consigam se ater a esse desenvolvimento e conseguirem né... quem sabe chegar a ser um jogador profissional, mas a gente quer primeiramente que o esporte seja saudável para eles, que eles continuem no esporte, que eles entrem no esporte e continuem até o final da vida. A gente na verdade é um professor-educador, a gente na verdade está formando cidadão para que ele se torne um jogador de futebol, um médico, um advogado, também toda uma questão de valores. Então a gente, na minha opinião, o professor que trabalha com iniciação, eu tenho essa visão que o professor 
é um professor-educador, tenho essa visão construtivista para criança, visão de formação do cidadão.

Professor 4: A gente procura conscientizar eles bastante que é uma escola de futebol, que a gente trabalha com formação, deixa bem claro, tanto para os alunos como para os pais que o importante é a prática do esporte, a questão social, deixa claro para eles que o Messi, o Neymar, o Cristiano Ronaldo que são exemplos de atletas, eles também passaram por escolinhas [...] Então a gente procura conscientizar eles de que virando atleta ou não, muitos desejam ser atletas de futebol, poucos conseguem, mas independente, sempre tem que permanecer fazendo o esporte, praticando e treinando.

\section{Escolarização:}

A possibilidade de ser jogador profissional faz com que ocorra casos em que a escola fique em segundo plano. As expectativas são altas para que seja um atleta de sucesso, sendo que em algumas ocasiões a família estimula que seja dada preferência ao futebol. Essas situações puderam ser verificadas nas escolas de futebol. O entrevistador questionou a respeito de como os professores observam nas rotinas das aulas de futebol a percepção dos alunos a respeito da escola de educação formal:

Professor 1: Muitos alunos aparecem aqui em um turno inverso querendo treinar, dizendo que não foram a aula, essas coisas. Até um pai uma vez disse que mandou o menino treinar. Ele disse que a mãe do menino falou para ir para aula, mas que ele pai disse que não precisava, que se o menino rodasse, rodou, porque ele (pai) também já havia rodado uma vez.

Há casos em que os alunos exigem que a escola formal seja uma reprodução da escola de futebol, em especial nas aulas de educação física. Relatam não ter motivação na escola formal: 
Professor 2: [...] eles reclamam mais assim, alguns deles, mais do professor de educação física que as vezes não querem fazer as vontades. Eu explico para eles: não é assim pessoal. Vocês têm que trabalhar assim, assim, assim... porque não é só futebol a aula de educação física, é outra proposta, existem outros esportes, outras coisas que vocês vão ter que trabalhar, futebol aqui conosco, aí sim, aí é diferente né, eles reclamam mais disso.

Existem casos em que os pais percebem que os filhos demonstram mais interesse no futebol do que na escola de educação formal e utilizam a escola futebol como fator motivador ou de negociação para que melhorem o desempenho escolar:

Professor 3: Os pais trazem bastante coisa, até porque a gente sabe que o esporte pode auxiliar nesse processo, alguns pais fazem até chantagens em relação ao esporte: "ah tá mal na escola, vou tirar meu filho do treino". Faltam alguns treinos por causa disso. Já aconteceu. A maioria das questões é em relação à desempenho escolar, às vezes ele está com alguma dificuldade e pede para conversar com o menino né, já que a gente sempre tem uma relação próxima com eles

Professor 4: [...] a gente sabe que as escolas, elas traçam os seus perfis e os alunos que estão lá dentro que se adequem ao perfil da escola. Infelizmente, acredito que a gente ainda não tem uma escola que consiga se adaptar a diversidade dos alunos [...] quando a família apresenta que o rendimento escolar está baixo, as notas estão baixas, que há o desinteresse por determinada matéria ou até pela escola como um todo, a gente procura se aproximar dos alunos. Uma primeira conversa, uma troca de ideias, tentar auxiliar de alguma forma. Caso não ajude, a gente começa a cortar de algumas convocações para jogos, que na verdade isso é o que mais interessa a eles. Eles fazem aula, eles treinam, mas o objetivo final é estar no time que vai para o jogo do campeonato. Então a gente corta da convocação, se isso não servir, a gente começa a trabalhar de forma diferente, mas é normal que haja o desinteresse ou notas baixas, de uma forma ou de outra sempre aparece, mas a gente procura trabalhar sempre em conjunto com a familia isso. 
O entrevistador questionou quais abordagens os profissionais adotam a respeito da escolarização em suas aulas:

Professor 1: Mais verbalmente, a gente sempre fala né: como está teu boletim? Mas nunca pede a fio, assim, todo mês, a cada trimestre. Não é uma regra, mas eu sempre tô cobrando eles, pergunto como é que tá no colégio, converso mais firme se o menino não tá muito legal, mas nada muito fixo assim.

Professor 2: A gente sempre tenta né...captar do pai se ele tá bem na escola, se está fazendo a tarefa de casa corretamente, eu preconizo isso. A criança, ela tem que ter autonomia né, e competência, que são duas necessidades básicas do indivíduo, além do relacionamento social. A gente sempre procura estar atento a essas questões, principalmente assim, da questão de boletim, de nota, quando o aluno tá mal a gente procura conversar com o aluno, saber o que tá acontecendo, se está com alguma dificuldade de estudar, está acontecendo alguma coisa com pai ou com a mãe. A gente sempre procura estar perto do aluno, dos pais e dos responsáveis, ter um feedback positivo e conseguir aconselhar a criança, dizer o que está acontecendo para ela poder se abrir e ter esse controle é bacana.

Professor 3: A gente criou algumas ferramentas, até foi proposto na reunião para acompanhar, fazer o acompanhamento do boletim, do parecer, e a ideia é fazer isso regular né, trimestral, para que eles possam trazer o rendimento da escola e a gente possa acompanhar e incentivar a que eles continuem tendo um desempenho bom.

Professor 4: Eu não tenho controle assim: apresentar nota, apresentar boletim, mas é justamente porque tem essa relação com as famílias. As famílias se sentem à vontade de mencionar para mim e para os demais professores, quando o rendimento escolar está baixo, porque eles sabem que a gente tem essa cobrança em cima dos meninos. Então a gente não 
tem essa cobrança de boletim e de notas, mas nossa relação com as famílias é muito próxima em relação a isso. Ter um bom rendimento escolar é parte essencial do aluno e do atleta de futebol da nossa escola.

\section{DISCUSSÃO}

Os profissionais de educação física, que atuam como professores de futebol, são conscientes de suas responsabilidades como agentes de educação nas escolas futebol. Todos profissionais reconhecem a importância da escolaridade no processo de formação dos atletas e de alguma forma tentam apresentar aos alunos, através de discussões em torno do assunto, questões pertinentes a educação formal nas conversas do início ou no final das aulas.

Demonstram ter conhecimento das dificuldades de acesso dos alunos ao ensino escolar de qualidade, devido a dualidade histórica existente no País e procuram abordar temas além do futebol em suas aulas. Dessa forma, caracterizam esses espaços para prática esportiva, como locais de educação não-formal.

Ressalta-se que todos os professores relataram que a família é parte fundamental nesse processo de conscientização dos alunos. Destacaram que sem a contribuição familiar, as tentativas de formação integral e valorização da escola são ineficientes.

Com relação à metodologia de ensino, os resultados indicam que os professores possuem um plano de ensino bem definido, com objetivos claros e divididos por parte inicial, desenvolvimento e parte final. Os procedimentos adotados pelos professores vêm ao encontro do que recomenda Freire (2006), que define um plano geral de aula de futebol dividido como parte inicial, destinada a roda de conversa; partes práticas, com brincadeiras, aquecimento, exercícios e jogos; e parte final, conversando sobre o que ocorreu na aula.

Destaca-se também que esse momento para conversas ou brincadeiras, possibilita um espaço democrático para troca de experiências e discussões. Nesse sentido, observa-se elementos típicos do trabalho como princípio educativo, não no sentido de formação profissional especializada, mas na possibilidade de proporcionar um espaço onde as múltiplas dimensões do ser humano podem ser desenvolvidas e não meramente as habilidades técnicas esportivas. 
Com relação ao itinerário formativo, os professores reconhecem as dificuldades para profissionalização no futebol e procuram informar os alunos a respeito dos possíveis contratempos que podem surgir. Destaca-se o cuidado que os profissionais tem para abordar o assunto respeitando as características de cada faixa etária, estimulando a prática do esporte como um hábito saudável para vida.

Quanto à escolarização, percebe-se que há um desinteresse em algumas oportunidades referente a escola de educação formal. Essas ocorrências podem ter complacência e estimulo da família ou ser de iniciativa exclusiva do aluno que não se vê motivado a estudar, seja por deslumbramento com o possível sucesso no futebol ou ausência de políticas educativas que possibilitem um ensino de qualidade a todos, conforme opinou um dos entrevistados.

Entretanto, observa-se na revisão de literatura, que fatores históricos contribuem para esse desinteresse. Inicialmente o futebol que era somente praticado por elites, popularizou-se até o ponto de ser marginalizado e ao longo tempo retoma o contexto do prestígio de ser um atleta com boa remuneração, mesmo sem escolaridade.

Contudo, independente da causa, verificou-se que as escolas de futebol podem colaborar, em parceira com as famílias, para que os alunos tomem consciência da importância da escola, independente dos possíveis problemas estruturais ou pedagógicos que a mesma possua.

A abordagem sobre escolarização nas aulas de futebol ocorre principalmente através de conversas durante as sessões de treinamento, a partir de iniciativa do professor ou quando ocorre queixa dos responsáveis pelos alunos. Nas escolas de futebol não há uma padronização que exija desempenho escolar para continuar nos treinamentos esportivos, entretanto, alguns responsáveis pelos alunos condicionam que o desempenho escolar seja satisfatório para que continuem na escola de futebol.

Os professores aconselham os alunos a não abandonar os estudos para dar preferência ao futebol, informando que a boa formação é importante em qualquer escolha profissional, inclusive a de atleta. Estimulam que o futebol deve ser visto como uma prática esportiva saudável, relatando que a pressão excessiva para profissionalização pode ser prejudicial e revelam aos alunos que muitas podem ser as causas que venham a impedir o profissionalismo, por essa razão, devem estudar para que possam optar por outra profissão caso seja necessário 


\section{CONSIDERAÇÕES FINAIS}

Esse estudo verificou que historicamente a profissionalização de atletas de futebol passou por transições marcantes e desde a fase amadora existe a discussão sobre a escolarização de atletas. No modelo atual, há muito prestígio na profissão de atletas de futebol e esse fato estimula que crianças e jovens priorizem o esporte, preterindo a escola de educação básica, com a esperança de fama e altos salários com mais facilidade do que atingiriam por meio dos bancos escolares.

Diante desse contexto, as escolas de futebol procuram contribuir para que seus alunos não abandonem os estudos, devido a imprevisibilidade do profissionalismo do futebol e a necessidade de formação adequada em qualquer área profissional. A atuação dos professores de futebol ocorre de maneira preventiva principalmente através de conversas com os alunos e a família.

O presente estudo não é conclusivo para definir a atuação das escolas de futebol como espaço efetivo para influenciar seus alunos a continuarem os estudos, contudo, revela as escolas esportivas como um espaço relevante para auxiliar as famílias nesse sentido. Sendo assim, consideramos que podem ser realizadas pesquisas futuras a respeito de quais ações são possíveis que as escolas esportivas e a escola formal podem realizar em conjunto.

\section{REFERÊNCIAS}

ANDRADE, Polyanna Peres. É muito mais que entrar em campo e defender um time: qualidade de vida no trabalho, bem-estar/mal-estar no trabalho e carreira de jogadores de futebol profissional. Tese (Doutorado em Psicologia Social) Universidade de Brasília, Brasília, 2016.

ANGELO, Luciana. Gestão de carreira esportiva: uma história a ser contada no futebol. Tese (Doutorado em Ciências) - Escola de Educação Física e Esporte, Universidade de São Paulo, São Paulo, 2014.

BRASIL. Decreto $n^{\circ} 5.154$ de 23 de julho 2004. Dispõe sobre as diretrizes e bases da educação nacional, e dá outras providências. Brasilia, DF: Presidência da República, 2004. Disponível em: http://www.planalto.gov.br/ccivil_03/_ato20042006/2004/decreto/d5154.htm. Acesso em: 23 de junho 2019.

BRASIL. Lei $n^{\circ}$ 9.394, de 20 de dezembro de 1996. Estabelece as diretrizes e bases da educação nacional. Diário Oficial da União: Seção 1, Brasília, DF, 23 dez. 
1996. Disponível em: http://www2.camara.leg.br/legin/fed/lei/1996/lei-9394-20dezembro-1996-362578-publicacaooriginal-1-pl.html. Acesso em: 02 de dez. 2018.

BRASIL. Lei $\mathbf{n}^{\circ} \mathbf{9 . 6 1 5}$, de 24 de março de 1998. Institui normas gerais sobre o desporto e dá outras providências. Diário Oficial da União: Seção 1, Brasília, DF, 25 mar. 1998. Disponível em: www2.camara.leg.br/legin/fed/lei/1998/lei-9615-24-marco1998-351240-publicacaooriginal-1-pl.html. Acesso em: 02 de dez. 2018.

BRASIL. Lei $\mathbf{n}^{0}$ 11.892, de 29 de dezembro de 2008. Institui a Rede Federal de Educação Profissional, Científica e Tecnológica, cria os Institutos Federais de Educação, Ciência e Tecnologia, e dá outras providências. Brasília, DF, 20 dez. 1998. Disponível em: http://www.planalto.gov.br/ccivil_03/_Ato20072010/2008/Lei/L11892.htm. Acesso em: 02 de dez. 2018.

CALDAS, Waldenyr. Pontapé inicial: memória do futebol brasileiro (1894-1933). São Paulo: Ibrasa, 1990. 234 p.

CARRAVETTA, Elio. Modernização da Gestão do Futebol Brasileiro: perspectivas para qualificação do rendimento competitivo. Porto Alegre: AGE, 2006. 206 p.

CBF. Regulamento de Registro e Transferência. Rio de Janeiro, 21 dez. 2017. Disponível em: https://conteudo.cbf.com.br/cdn/201712/20171221163729_0.pdf. Acesso em: 5 jul. 2019.

CORREIA, Carlus. Projetos familiares na formação de atletas no futebol: apostas na profissionalização e na escolarização. Tese (doutorado) - Faculdade de Educação, Universidade Federal do Rio de Janeiro, Rio de Janeiro, 2018.

COUTO, Hergos. Esporte do oprimido: utopia e desencanto na formação do atleta de futebol. Tese (doutorado) - Faculdade de Educação, Universidade Nove de Julho, UNINOVE, São Paulo, 2012.

FREIRE, João Batista. Pedagogia do futebol. 2. ed. Campinas: Autores Associados, 2006. 98 p.

FRIGOTTO, Gaudêncio. Teoria e Práxis e o antagonismo entre a formação politécnica e as relações sociais capitalistas. Trabalho, Educação e Saúde, Rio de Janeiro, v. 7, p. 67 - 82, 2009. Acesso em: 10 de julho de 2019.

MARQUES, Maurício; SAMULSKY, Dietmar. Análise da carreira esportiva de jovens atletas de futebol na fase de transição da fase amadora para fase profissional: escolaridade, iniciação, contexto sócio-familiar e planejamento de carreira. Revista Brasileira de Educação Física e Esporte, São Paulo, v.23, n.2, p. 103-119, abr/jun. 2009.

MANFREDI, Silvia M. Educação Profissional no Brasil. São Paulo: Cortez, 2002. $317 \mathrm{p}$.

MINISTÉRIO DO TRABALHO E EMPREGO. Classificação Brasileira de Ocupações. Disponível em: 
http://www.mtecbo.gov.br/cbosite/pages/downloads.jsf;jsessionid=bXe1WNJB50a4q bE9RkWC6yj0.slave26:mte-cbo. Acesso em: 2 dez. 2018.

MOURA, Dante. Educação Básica e Educação Profissional Tecnológica: dualidade histórica e perspectivas de integração. Holos, Rio Grande do Norte, ano 23, n. 2, 2007. Disponível em:

http://www2.ifrn.edu.br/ojs/index.php/HOLOS/article/view/11/110. Acesso em 10 de julho 2019.

RAMOS, Marise. Ensino Médio e educação profissional: dualidade histórica e possibilidades de integração. In: MOLL, Jaqueline et al (Org.) Educação

profissional e tecnológica no Brasil contemporâneo: desafios, tensões e possibilidades. Porto Alegre: Artmed, 2010. P. 42-57.

RIVITI, Thiago. Futebol brasileiro na atualidade: história, cultura e profissionalização. Dissertação (Mestrado em Psicologia) - Faculdade de Ciências e Letras de Assis, Universidade Estadual Paulista, Assis, 2016.

ROCHA, Hugo. O futebol como carreira, a escola como opção: o dilema do jovem atleta em formação. Tese (doutorado) - Faculdade de Educação, Universidade Federal do Rio de Janeiro, Rio de Janeiro, 2017.

ROQUE, Moraes. Análise de conteúdo. Revista Educação, Porto Alegre, v. 22, p. $7-32,1999$.

SAVIANI, Dermeval. $O$ trabalho como princípio educativo frente às novas tecnologias. In: FERRETI, C. ET alii. Novas tecnologias, trabalho e educação: um debate multidisciplinar. Petrópolis: Vozes, 1994

SAVIANI, Dermeval. Trabalho e Educação: fundamentos ontológicos e históricos. Revista Brasileira de Educação, Rio de Janeiro, v. 12, p. 152 - 180, jan./abr. 2007. Disponível em: http://www.scielo.br/pdf/rbedu/v12n34/a12v1234.pdf. Acesso em: 23 de junho de 2019. 